\title{
A Florentine School of Physics and Optics.
}

By Dr. L. C. MARTin.

THE city of Florence, deservedly famous as a place of pilgrimage for lovers of art, is no less worthy of a visit on the part of students of science. The famous Museo di Fisica, with its Tribuna di Galilei and its collection of priceless instruments, will always attract the lion's share of attention, but a visit to the charming southern suburb of Arcetri, with the astronomical observatory and the newly erected Institute of Physics and Optics, will amply repay the time spent in making it.

On driving out from the city by the cypress avenue of the Villa Poggio Imperiale, the observatory is seen to the left crowning a lofty hill, on the side of which the red roofs of the Institute can be seen among the green of the surrounding gardens and vineyards. A wide view over the peaceful countryside is obtained on reaching the terrace.

The building is of the square form with centre

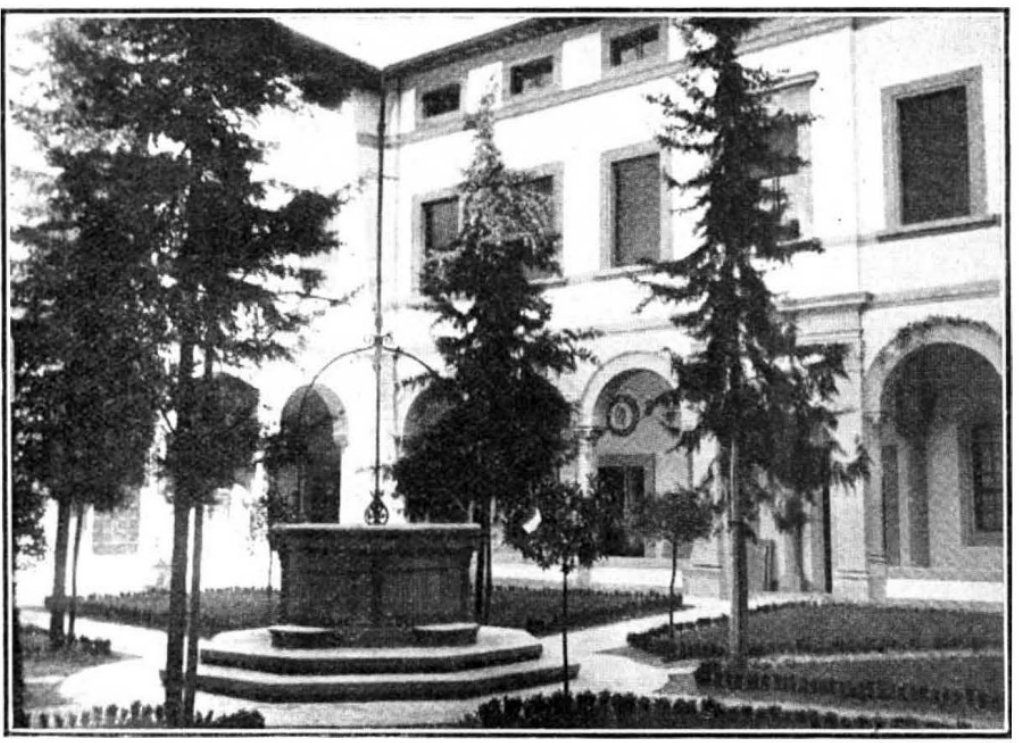

FIG. I. - The Courtyard of the Physical Institute at Arcetri, Florence. University of Pisa.

under the direction of Prof. A. Garbasso, who, during the last year, has served as Mayor of Florence. The optical laboratory is directed by Prof. A. Occhialini, the well-known editor of the Revista d' Ottica. In the coming year it is proposed to build an annexe devoted entirely to technical optics. Up to the present the teaching activity has been restricted to the physical side, but courses on optical subjects are being arranged and research and testing are already in progress. Accommodation is provided for thirty to forty students taking post-graduate courses in physics. The present students are drawn largely from the

In the course of a short visit it is scarcely possible to notice all the features deserving attention. The arrangement of lecture theatre, class rooms, and research rooms is generally excellent, and it is evident that the needs of experimental work have been considered during design ; for example, in one corner of the building it is possible to obtain the equivalent of a vertical circular shaft by removing the coverings of holes in the roof and floors, an arrangement which is of the greatest value in optical testing.

The usual wiring and switchboard for the distribution of electric current is provided, and there is also a separate high-tension circuit. Another point which seems admirable is the construction of the roomy apparatus cupboards in which three sides are of glass; they stand in the corridor on the first floor and exhibit the apparatus to advantage, a matter of importance in a teaching institution.

In the matter of equipment the usual lines have been generously followed. For example, the optical apparatus includes 40 and 20 plate echelons with appropriate spectroscopes, a Fabry and Perot interferometer, and a

courtyard usual in Italy, and is only two stories high. A cloister surrounds the courtyard on the ground level, and above the cloister a wide closed corridor affords interconnexion between the rooms on the upper floor. It is commonly held that a similar form of building is not suitable for the British Isles on account of the colder climate, but it may be doubted whether this view is correct; the arrangement has in the present case certainly proved most successful from many points of view. The rooms and corridors are light and airy, while the building is extremely compact and its low height makes for stability. There is little or no trouble from vibration, all machinery being housed in one side of the square at the back of the building. Lastly, and not least, a way has been found to combine beauty with utility, and it was not thought wasteful even in these modern times to follow the charming traditions of Florence by planting a garden to surround the well in the courtyard. This is shown in Fig. I.

The Institute was erected immediately after the war to serve for post-graduate and research work in physics and optics. The physical laboratories are Nutting spectrophotometer, all by A. Hilger, Ltd. There is also a large spectrometer (with four reading microscopes for the circle) by the Société Genevoise. Other branches of physics seem to be supplied in a corresponding manner. Those who know something of the present cost of equipment of this kind will appreciate the intensity and vigour of the effort which Italy is making in the founding of this Institute.

In Florence as in few other cities one loses that sense of the remoteness of the past which oppresses the mind in more modern surroundings, and the splendour of bygone days seems still our own for guidance and inspiration. Such thoughts find a fitting expression in two frescoes which are seen on leaving the Institute by the main staircase. On the one side is seen Youth in the quietness and cool of the evening drinking of the fountain of ancient wisdom, while opposite we see Humanity in the glory of morning sunlight pressing upwards with eagerness and hope towards the hilltops.

I am indebted to Profs. Occhialini and Garbasso for photographs and information for the purposes of this article.

NO. 2762 , VOL. I IO] 